\title{
ACQUIRED HEMOPHILIA RELATED TO MIXED CONNECTIVE TISSUE DISEASE: CASE REPORT
}

\begin{abstract}
Bruno Carnevalli1, ${ }^{1,}$ Fabio Tadayoshi Sazaki Junior ${ }^{2}$, Rodrigo Maldonado Franco ${ }^{1}$, lurik Kooiti Uchida ${ }^{1}$, Milene Tieno Sakata Vasconcellos ${ }^{1}$, Gustavo Lawin ${ }^{1}$, Joao Paulo Frasson ${ }^{1}$, Anna Herminia Castro Gomes de Amorim¹, Luiz Eduardo de Paula ${ }^{1}$, Cecilia

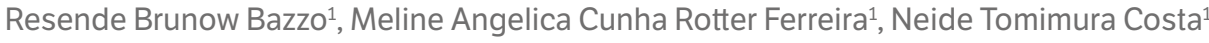

1.Universidade Estadual de Londrina, Londrina (PR), Brazil; 2.Universidade Federal de São Paulo, São Paulo (SP), Brazil.

*Corresponding author: brunocarnevalli.bc@gmail.com

\section{BACKGROUND}

Acquired hemophilia is a rare disorder mostly associated with circulating antibodies against a coagulation factor, mainly factor VIII. It is related to diverse autoimmune diseases, such as systemic erythematous lupus and rheumatoid arthritis. On this report, we will describe a case of a patient with diagnosis of mixed connective tissue disease (MCTD) and acquired hemophilia.

\section{CASE REPORT}

A 37-year-old brown-skinned female was admitted due to a 5-year history of Raynaud phenomenon, diffuse edema and arthritis in hands, sclerodactyly and 2 months of spontaneous progressive cutaneous hematomas in superior and inferior members (Figure 1). Following investigation: Complete blood cell count: hemoglobin $10.3 \mathrm{~g} / \mathrm{dL}$, hematocrit 32.4\%, MCV 96.4 fL, MCH 30.7 pg, total white cells $8250 / \mu \mathrm{L}$, platelets 262,000/ $\mu \mathrm{L}$; $11.7 \mathrm{~s}$, RNI 0.98, aPTT incoagulable; ANA 1:640 nuclear speckled pattern, anti-RNP 134.4UI; anti-Sm, anti-dsDNA, anticentromere, anti-Scl70, rheumatoid factor and lupus anticoagulant screen negatives; CT scan of thorax: interstitial lung disease; transthoracic echocardiogram: PSAP $40 \mathrm{mmHg}$; esophageal manometry: hypotonic superior and inferior esophageal sphincter and hypocontractility and aperistalsis on the esophageal body. We closed the diagnosis of MCTD, being prescribed prednisone $0.5 \mathrm{mg} / \mathrm{kg} /$ day. The patient presented improvement on the arthritis but without improvement of the hematomas and aPTT remained incoagulable, which was unexplained by the disease. Due to prolonged aPTT with normal platelets, we considered probable commitment of the intrinsic way of the coagulation cascade and made a mixing test, that consists on mixing aPTT of patient plasma with normal pooled plasma on equal proportion. When there are coagulation inhibitors, generally antibodies, test shows persistent prolongation of aPTT which happened on the patient. Thus, we came to the diagnosis of acquired hemophilia. The dose of prednisone was increased to $1 \mathrm{mg} / \mathrm{kg} / \mathrm{day}$ and began cyclophosphamide $0.5 \mathrm{mg} / \mathrm{m}^{2} \mathrm{monthly}$. Treatment response was satisfactory within 6 months, with important improvement of hematomas (Figure 2) and stabilization of aPTT resulting in complete withdraw of corticoid.

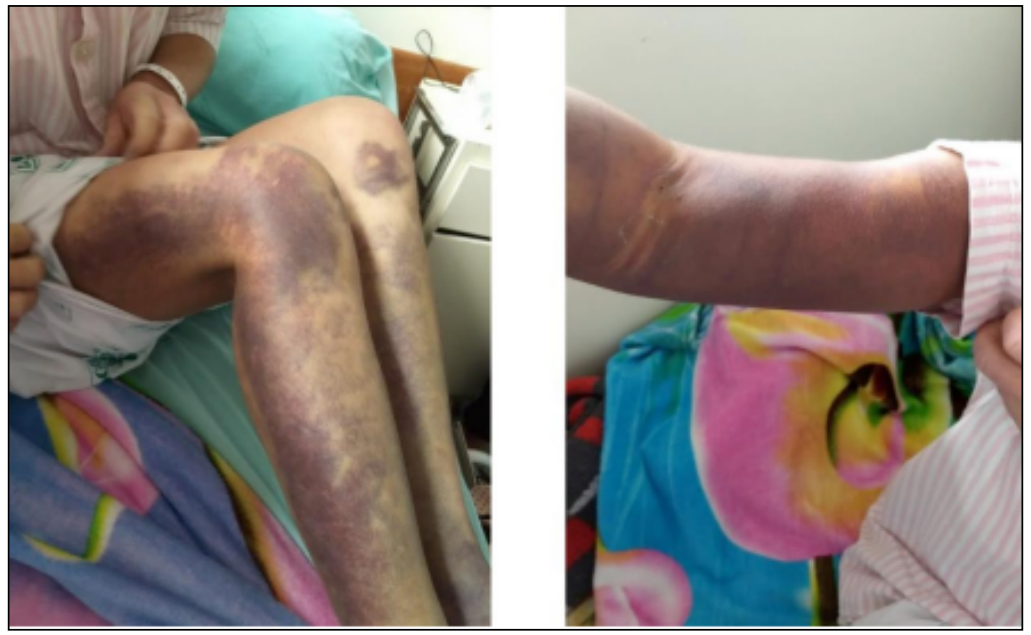

Figure 1. Bruises on legs, thighs and right arm.

Realização: 


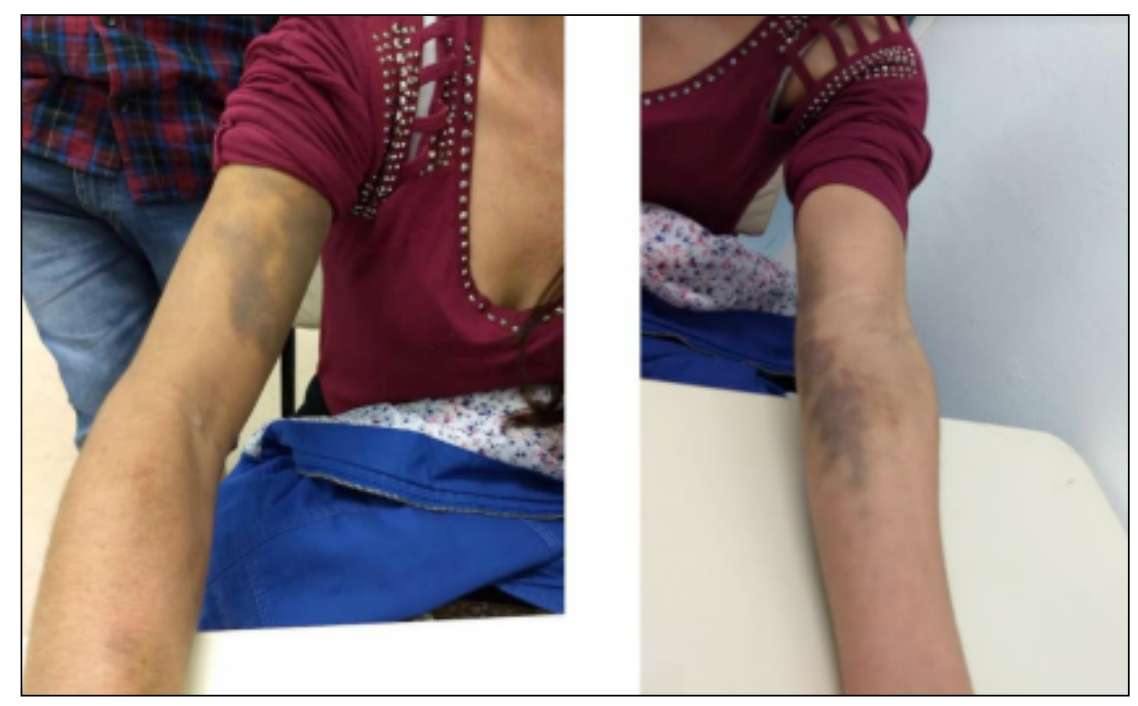

Figure 2. Bruises on upper limbs.

\section{CONCLUSION}

We presented a case of acquired hemophilia related to MTCD, that was successfully treated. We conclude that suspicion and investigation of this diagnosis is required in patients with autoimmune diseases and hemorrhagic phenomenon on the presence of prolonged aPTT and normal platelets.

\section{KEYWORDS}

Hemophilia, Mixed, Connective, Tissue, Disease. 